\title{
Computational Modelling for Specific Heat and Thermal Conductivity of Austenitic Stainless Steels Alloys at Solid Phase
}

\author{
Abdel-Baset H. Mekky \\ Department of Physics, College of Science and Arts El-Mithnab, Qassim University, El-Mithnab 51931, Saudi Arabia
}

Corresponding Author Email: A.Mekky@qu.edu.sa

https://doi.org/10.18280/rcma.300104

Received: 15 October 2019

Accepted: 2 December 2019

\section{Keywords:}

austenitic steel alloy, thermal conductivity, specific heat, software tool JMATPRO®, temperature

\begin{abstract}
This work studied the special effects of the temperature on a number of austenitic stainless steels that are AISI 316, 316L, 304, and 304L Alloys at a solid phase. JMATPRO®, a computer program for modeling of material properties was used to simulate these alloys. The validity of the mathematical model is established by comparing the simulation outcomes with the parallel experimental results. The thermal conductivity and the specific heat of solid-phase fundamentally change with temperature. Calculated specific heat capacity at room temperature agrees very well with Dulong-Petit prediction, but is significantly smaller than those in the literature. It is brought into being that the thermal conductivity and the specific heat basically increase with temperature increases. Generally, the simulation results offered in this study are found to be in good agreement with the experimental results. Thus, the validity and applicability of the JMATPRO® model are established.
\end{abstract}

\section{INTRODUCTION}

Austenitic stainless steels are considered by good toughness and corrosion resistance; they are furthermore the furthermost common types of stainless steels [1]. Austenitic stainless steels are frequently used in structural uses in oxidative or aqueous environments because of their great corrosion resistance joined with comparatively high ductility, strength, and toughness [2]. As such, they are extensively used for numerous large components in coolant systems of nuclear power plants, for example, pump and piping casings [3]. Above room temperature and at low temperatures, thermal conductivity and specific heat are relatively more sensitive. Thermal conductivity and specific heat for low temperatures had been evaluated for stainless steel [4-6]. The thermal conductivities of 20 various plates of steel that were designated as usual samples of commercial alloys used for different purposes and were predictable to have significantly different thermal conductivities, were determined [7].

Thermal conductivity and specific heat are the greatest essential properties for simulation of cooling and heating methods in heat treatment [8]. Numerical investigation for stainless steel forming has been commonly and rapidly employed in a lot of industrial areas for the last years [9-12]. JMATPRO ${ }^{2}$ 's capability to simulate the thermophysical properties has been done in earlier published studying for several metallic systems very well [13-15]. Thermal stability is a key feature of alloys intended for long-term service at elevated temperatures [16]. Thermo-physical and physical properties are critical parameters for processing simulation of steels. An extensive database has been created within the development of JMATPRO ${ }^{\circledR}$ for the calculation of physical and thermophysical properties which is linked to its thermodynamic calculation capability [17]. One qualitative disparity between the model and the experiments was that the measurement included a larger degree of asymmetry on either side of the weld than predicted by the model [18].

The aim of this work is to evaluate some thermophysical properties such as specific heats and thermal conductivity of some austenitic stainless steel alloys as a function of the temperature at the solid phase. In order to achieve this objective, JMATPRO ${ }^{\circledR}$ is used. With a view to certifying such properties, experimental results will be used to compare with the calculated results.

\section{CHEMICAL COMPOSITION}

KEI Industries Ltd. possesses a very severe check on the composition of stainless steel raw materials to reassure its customer's requirements. The standard composition of many grades of Stainless Steel presented by KEI Industries Ltd. is specified below [19].

AISI 316 and 304 are the high carbon supporter of the type austenitic stainless steel than AISI 316L and 304L that of the low carbon typical. The decreased carbon content develops its resistance to corrosion.

\section{NUMERICAL AND MODELING TECHNIQUE}

The software tool JMATPRO®, which is an acronym for Java-based Materials Properties software, is a suite of computer programs that have been developed by Thermotech Ltd. and Sente Software Ltd. for the prediction of a broad range of materials properties [20]. JMATPRO ${ }^{\circledR}$ started in 1998 as a project funded by a consortium of companies and institutions interested in expanding their materials properties 
modeling capacity. The CALPHAD-book [21] can be seen as a starting point and scientific foundation of the system. The initial release of JMATPRO ${ }^{\circledR}$ was available in 2002, the current release of JMATPRO ${ }^{\circledR}$ is V.6.2. The various compositions were given in JMATPRO ${ }^{\circledR}$ software to determine thermal conductivity and specific heat of some austenitic stainless steel alloys for solid-phase at varying temperatures.

\section{RESULTS AND DISCUSSIONS}

Specific heat $(\mathrm{C})$ is defined as, the amount of heat that has to be introduced or extracted to or from $1 \mathrm{~kg}$ of material to increase or decrease the material temperature by $1 \mathrm{~K}$.

$$
\mathrm{C}=\frac{\mathrm{dU}}{\mathrm{dT}}=\mathrm{Q} /(\mathrm{m} \cdot \Delta \mathrm{T})
$$

where,

$$
\begin{aligned}
& \mathrm{c} \text { - Specific heat, } \mathrm{J} /(\mathrm{kg} . \mathrm{K}) \\
& \mathrm{U} \text { - Internal energy } \mathrm{J} / \mathrm{kg} \\
& \mathrm{Q} \text { - Heat, J } \\
& \text { m - Material mass, } \mathrm{kg} \\
& \text { T - Temperature, K }
\end{aligned}
$$

Specific heat is essential to evaluate the energy of a system. Specific heat is the quantity that demonstrates the amount of heat required to change the temperature of the material. High specific heat assistances become stable material elements thus reducing the possibility of material failure. Moreover, specific heat is also significant in the valuation of deposited energy in the material.

Specific heat of austenitic stainless steels (316, 316L, 304 and 304L), is presented in Figure 1 (from a to d), respectively. Experimental and calculated specific heat (exp. And call.) for 316 [22], 316L [23], 304 [24] and 304L [23] alloys, as a function of temperature, are plotted for comparison.

The increase in the specific heat $(\mathrm{C})$ at temperatures is approximately proportional to $\mathrm{T}^{3}$. This behavior of the materials can well give details employing Debye model [25]:

$$
\mathrm{C}=\mathrm{a} \cdot \mathrm{T}^{3}
$$

where, (a) is a material-specific coefficient.

The specific heat curves of alloys roughly closed to the Debye model. As can be seen in Figure1 (from a to d), the values expected are well matched to the experimental values. As predictable, $C$ increases with $\mathrm{T}$ in contact with Debye's model [25]. No anomaly is observed.

The specific heat of the AISI 316, 316L, 304, and 304L alloys increases with increasing temperature in nearly a linear style (Figure 1).

From Table 1 and Figure 2, it is noticed that our calculated specific heat values $(C)$ are $0.44515,0.44562,0.45204$ and 0.45189 and experimental values are $0.468,0.499,0.45$ and $0.510 \mathrm{~J} / \mathrm{g}-\mathrm{K}$ for AISI 316, 316L, 304, and 304L alloys, respectively, at solid phase at $298.15 \mathrm{~K}$ are considerably lesser than $0.75 \mathrm{~J} / \mathrm{g}-\mathrm{K}$ presented in the US Military Handbook [26] which is also approved in 2006 by (ESA) the European Space Agency in (ESMDB) the European Space Materials database and Medical Device Handbooks [27]. From the time when the original source of the previously mentioned $C$ values is not specified, it is difficult to think through the causes of this considerable discrepancy. Though, our value reaches agreement with an evaluated by Dulong-Petit law [28, 29], that says for materials at room temperature, $C=3 R$, where $R$ is the gas constant $8.31 \mathrm{~J} / \mathrm{K}$-mole. Established on the average molar weight of AISI 316, 316L, 304, and 304L alloys considered from the composition in Table 2, the expected value is $C=0.423 \mathrm{~J} / \mathrm{g}-\mathrm{K}$, in a good close to our calculated $C$ value.
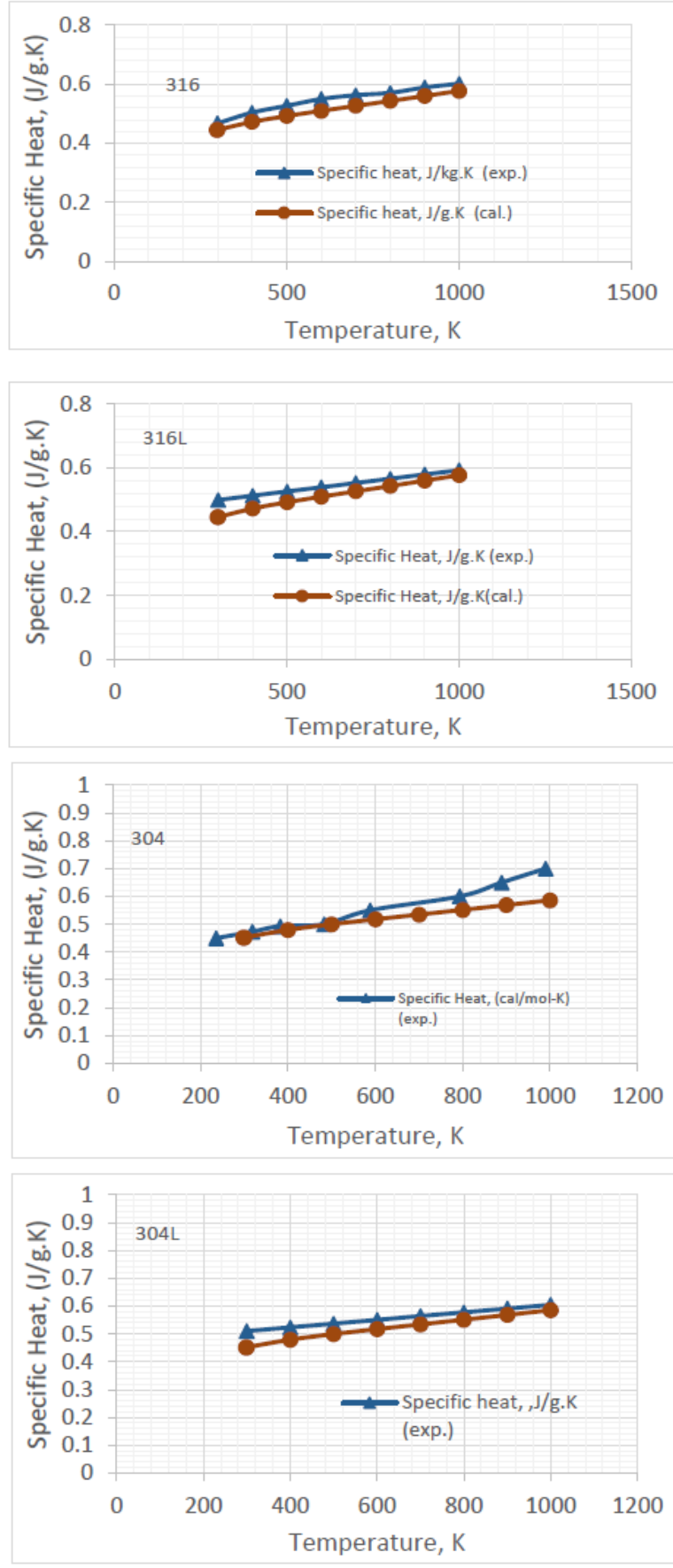

Figure 1. Comparison between experimental (exp.) and calculated (cal.) specific heat for 316 [22], 316L [23], 304 [24] and 304L [23] alloys, as a function of temperature 


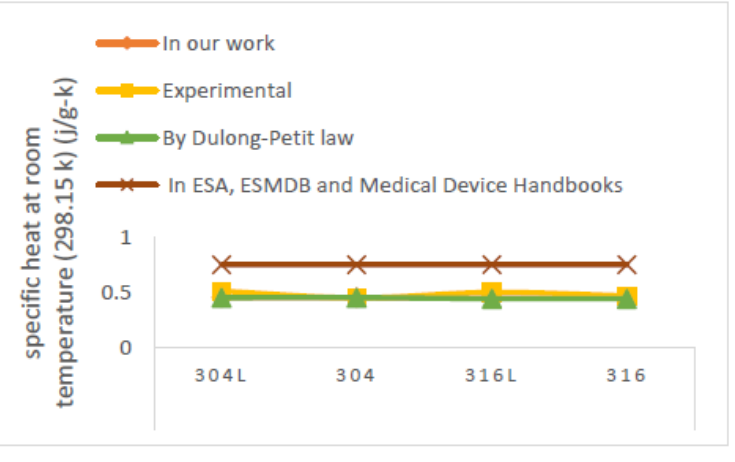

Figure 2. Calculated, experimental values of specific heat, the estimate by Dulong-Petit law, tabulated in (ESA), (ESMDB) and Medical Device Handbooks, for AISI 316, 316L, 304, and 304L alloys, respectively, at the solid phase
Table 1. Calculated, experimental specific heat values, the estimate by Dulong-Petit law, tabulated in (ESA), (ESMDB) and Medical Device Handbooks, for AISI 316, 316L, 304, and $304 \mathrm{~L}$ alloys, respectively, at the solid phase

\begin{tabular}{|c|c|c|c|c|}
\hline \multirow[t]{2}{*}{ Types } & \multicolumn{4}{|c|}{$\begin{array}{l}\text { specific heat at room temperature } \\
(298.15 \mathrm{~K})(\mathrm{J} / \mathrm{g}-\mathrm{K}) \text { for: }\end{array}$} \\
\hline & 316 & $316 \mathrm{~L}$ & 304 & $304 \mathrm{~L}$ \\
\hline In our work & 0.44515 & 0.44562 & 0.45204 & 0.45189 \\
\hline Experimental & 0.468 & 0.499 & 0.45 & 0.510 \\
\hline $\begin{array}{l}\text { By Dulong-Petit } \\
\text { law }\end{array}$ & 0.44183 & 0.44163 & 0.45129 & 0.45105 \\
\hline $\begin{array}{c}\text { In ESA, ESMDB } \\
\text { and Medical } \\
\text { Device } \\
\text { Handbooks }\end{array}$ & 0.75 & 0.75 & 0.75 & 0.75 \\
\hline
\end{tabular}

Table 2. Chemical composition of the austenitic stainless steel alloys used in the present work (wt \%)

\begin{tabular}{|c|c|c|c|c|c|c|c|c|c|c|}
\hline \multicolumn{2}{|c|}{ Type wt\% } & C & Mn & P & S & Si & Cr & Ni & Mo & Fe \\
\hline \multirow{2}{*}{316} & Standard & 0.08 & 2 & 0.045 & 0.03 & 1 & $16.5 / 18.5$ & $10 / 13$ & $2.5 / 3$ & Balance \\
\cline { 2 - 11 } & Tested & 0.08 & 1.74 & 0.012 & 0.01 & 0.73 & 17.3 & 13.1 & 2.66 & 64.368 \\
\hline \multirow{2}{*}{ 316L } & Standard & 0.03 & 2 & 0.045 & 0.03 & 1 & $16 / 18$ & $10 / 14$ & $2 / 3$ & Balance \\
\cline { 2 - 11 } & Tested & 0.023 & 1.74 & 0.012 & 0.01 & 0.73 & 17.3 & 13.1 & 2.66 & 64.425 \\
\hline \multirow{2}{*}{304} & Standard & 0.08 & 2 & 0.045 & 0.03 & 1 & $18 / 20$ & $8 / 10$ & - & Balance \\
\cline { 2 - 10 } & Tested & 0.08 & 1.74 & 0.012 & 0.01 & 0.73 & 17.3 & 10 & - & 70.128 \\
\hline \multirow{2}{*}{ 304L } & Standard & 0.03 & 2 & 0.045 & 0.03 & 1 & $18 / 20$ & $8 / 12$ & - & Balance \\
\cline { 2 - 10 } & Tested & 0.023 & 1.74 & 0.012 & 0.01 & 0.73 & 17.3 & 10 & - & 70.185 \\
\hline
\end{tabular}
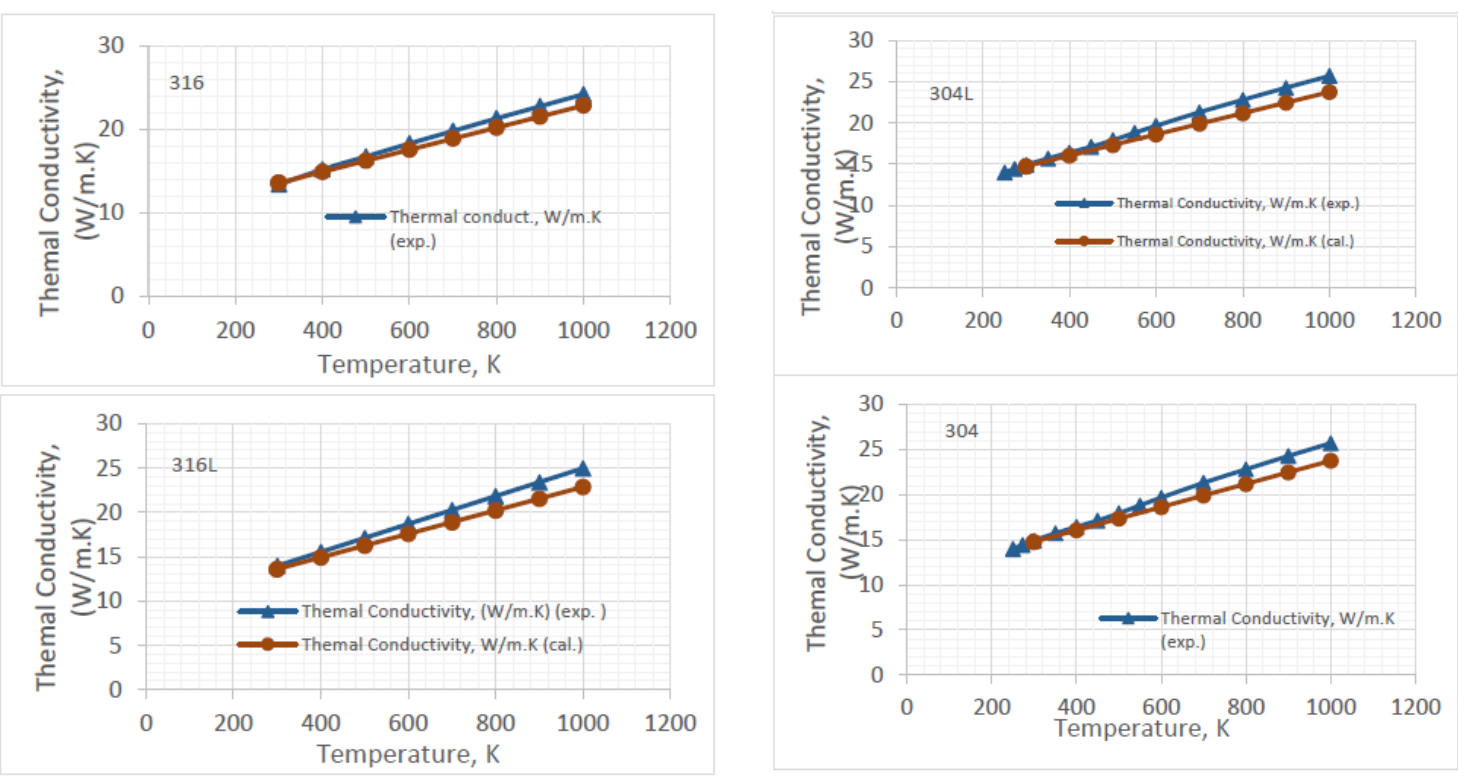

Figure 3. Comparison between experimental (exp.) and calculated (cal.) thermal conductivities for 316 [22], 316L [23], 304 [24] and $304 \mathrm{~L}$ [23] alloys, as a function of temperature

Thermal conductivity is considered as the greatest important property of any alloy for heat transfer uses. The multilinear regression model has been found to fit better the thermal conductivity of metals as a function of temperature [30], as the form:

$$
k=a T^{b} e^{c T} e^{d / T}
$$

where,

$\mathrm{K}$ - is the thermal conductivity $\left(\mathrm{W} \cdot \mathrm{m}^{-1} \cdot \mathrm{K}^{-1}\right)$,

$\mathrm{T}-i$ s the temperature $(\mathrm{K})$ $\mathrm{a}, \mathrm{b}, \mathrm{c}$, and $\mathrm{d}$ - are fitting constants.

Figure 3 shows the calculated thermal conductivity versus temperature of $316,316 \mathrm{~L}, 304$ and 304L alloys. The measured experimental data from other sources [22-24] and the paper for the alloys in our valuation work as a function of temperature also scheme for comparison [23].

The thermal conductivities of all tested alloys were found to be linear functions of temperature in the variety of temperatures in which work was made. Thermal conductivity increasing as temperature increases. For alloys, at low temperatures, the heat is carried mostly by the free electrons 
so that the thermal conductivities increase with the increase in temperature.

Figure 3 displays a comparison between the experimental and calculated values for the thermal conductivities of the tested alloys. As can be seen in Figure 3, the values predicted are good compared to the experimental values.

From Figures 1 and 3 was noticed that the presence of carbon in some austenitic stainless steels had a lower significance effect on the thermal conductivity and the specific heat. Carbon did not have the greatest significance effect that is because of its strong influence on the conversion of austenite to ferrite, the paper [1] and the significance of the extensive variety of heat treatments possible.

\section{CONCLUSIONS}

The objectives of the present investigation are to study the thermal conductivity and the specific heat of some austenitic stainless steels, to identify the effects upon property behavior that have been shown to be due to temperature. Specific Heat and thermal conductivity vs. temperature curves were calculated for some Austenitic Stainless Steels Alloys at Solid Phase alloys. The tested stainless steels are AISI 316, 316L, 304, and 304L. A comparison with reported experimental behavior is generally very good. Where significant discrepancies occur clear questions arise as to the validity of the experimental result. The measured specific heat at room temperature agrees very well with Dulong-Petit prediction but is considerably smaller compared with those in the literature. The recommended values include the thermal conductivity and the specific heat of the solid phase are critical components in casting simulations, all as a function of temperature. Thermal conductivities of alloys at ambient and elevated temperatures. In general, a good agreement exists between the experimental and simulation results for the temperature. The outcomes of this research demonstrated that it is possible to usage JMATPRO ${ }^{\circledR}$ software for predicting the thermal conductivity and the specific heat for all tested steel types for temperatures. Conclusion JMATPRO ${ }^{\circledR}$ software can predict the thermal conductivity and the specific heat of steels very successfully. The work simply analyzed the influence of carbon on the thermophysical properties of the materials. So, in the future, we will try to analyze the microstructure at different temperatures and explain the reasons for the differences between the experimental results and the simulation results by other software packages.

\section{REFERENCES}

[1] Abu-Eishah, S.I. (2001). Correlations for the thermal conductivity of metals as a function of temperature. Int $\mathrm{J}$ Thermophys, 22(6):

$1855-68$ https://doi.org/10.1023/A:1013155404019

[2] Agapiou, J.S., DeVries, M.F. (1989). An experimental determination of the thermal conductivity of a 3041 stainless steel powder metallurgy material. J Heat Transfer, 111(2): https://doi.org/10.1115/1.3250675

[3] Ashworth, T., Smith, D.R. (1985). Thermal Conductivity 18. Springer US, Boston, MA.

[4] ASM International. (2009). Materials and Coatings for Medical Devices Cadiovascular. Materials Park, Ohio
44073-0002.

[5] Bogaard, R.H., Desai, P.D., Li, H.H., Ho, C.Y. (1993). Thermophysical properties of stainless steels. Thermochim Acta, 218(C): 373-93. https://doi.org/10.1016/0040-6031(93)80437-F

[6] Marquardt, E.D., Le, J.P., Radebaugh, R. (2002). Cryogenic Material Properties Database. In: Ross R.G. (eds) Cryocoolers 11. Springer, Boston, MA. https://doi.org/10.1007/0-306-47112-4_84

[7] Sheiton, S. M. (1934). Thermal conductivity of irons and steels. Bureau of Standards Journal oj Research, 12(5): 441-450. https://10.1016/s0016-0032(34)90359-8

[8] Centre, S.T., Surrey, T., Centre, S.T., Surrey, T. (2003). Modelling of the thermo-physical and physical properties for solidification of al-alloys. Light Metals, 9(3): 723743. https://doi.org/10.1007/978-3-319-48228-6_62

[9] Daoud, S., Bioud, N., Saini, P.K. (2019). Finite temperature thermophysical properties of $\mathrm{MgCu}$ intermetallic compound from quasi-harmonic Debye model. J Magnes Alloy, 7(2): 335-44. https://doi.org/10.1016/j.jma.2019.01.006

[10] Guo, Z.L., Turner, R., Da Silva, A.D., Sauders, N., Schroeder, F., Cetlin, P.R., Schillé, J.P. (2013). Introduction of materials modelling into processing simulation. Mater Sci Forum, 762(2): 266-76. https://doi.org/10.4028/www.scientific.net/MSF.762.26 6

[11] Gusev, Y.V. (2016). The field theory of specific heat. Russian Journal of Mathematical Physics, 23(1): 56-76. https://doi.org/10.1134/S1061920816010040

[12] Hama, T., Kariyazaki, Y., Hosokawa, N., Fujimoto, H., Takuda, H. (2012). Work-hardening behaviors of magnesium alloy sheet during in-plane cyclic loading. Materials Science and Engineering: A, 551: 209-217. https://doi.org/10.1016/j.msea.2012.05.009

[13] Larsson, C., Holden, T.M., Bourke, M.A.M., Stout, M., Teague, J., Lindgren, L.E. (2005). Measurement and modeling of residual stress in a welded Haynes ${ }^{\circledR} 25$ cylinder. Materials Science and Engineering: A, 399(12): 49-57. https://doi.org/10.1016/J.MSEA.2005.02.026

[14] Leffler, B. (1996). Stainless steels and their properties. AvestaPolarit AB, 1-45.

[15] Lou, X.Y., Li, M., Boger, R.K., Agnew, S.R., Wagoner, R.H. (2007). Hardening evolution of AZ31B Mg sheet. Int. J. Plast., 23(1): 44-86. https://doi.org/10.1016/j.ijplas.2006.03.005

[16] Massidda, L., Varone, A. (2008). A numerical analysis of a high temperature solar collecting tube, using helium as a heat transfer fluid. SolarPaces.

[17] Mills, K.C., Yuchu, S.U., Zushu, L.I., Brooks, R.F. (2004). Equations for the calculation of the thermophysical properties of stainless steel. ISIJ International, 44(10): https://doi.org/10.2355/isijinternational.44.1661

[18] Piazza, R. (2018). The strange case of Dr. Petit and Mr. Dulong. History and Philosophy of Physics.

[19] Pike, L.M. (2012). Long term thermal exposure of HAYNES 282 alloy. Superalloy 718 Deriv, 644-660. https://doi.org/10.1002/9781118495223.ch50

[20] Proust, G., Tomé, C.N., Jain, A., Agnew, S.R. (2009). Modeling the effect of twinning and detwinning during strain-path changes of magnesium alloy AZ31. International Journal of Plasticity, 25(5): 861-880. https://doi.org/10.1016/j.ijplas.2008.05.005 
[21] Saunders, N., Guo, Z., Li, X., Miodownik, A.P., Schillé, J.P. (2003). Using JMatPro to model materials properties and behavior. JOM, 55(12): 60-65. https://doi.org/10.1007/s11837-003-0013-2.

[22] Saunders, N., Miodownik, P. (1998). CALPHAD (Calculation of Phase Diagrams): A Comprehensive Guide, Volume 1. Hardcover ISBN: 9780080421292.

[23] Schwarm, S.C., Kolli, R.P., Aydogan, E., Mburu, S., Ankem, S. (2017). Characterization of phase properties and deformation in ferritic-austenitic duplex stainless steels by nanoindentation and finite element method. Materials Science and Engineering: A, 680: 359-67. https://doi.org/10.1016/j.msea.2016.10.116

[24] Taylor, P., Schillé, J., Guo, Z., Saunders, N., Miodownik, A.P., Schillé, J., Guo, Z., Saunders, N., Miodownik, A.P. (2011). Materials and manufacturing processes modeling phase transformations and material properties critical to processing simulation of steels. Materials and Manufacturing Processes, 137-143. https://doi.org/10.1080/10426910903153059

[25] The, O. (1934). Thermal conductivity of irons and steels. Journal of the Franklin Institute, 217(5): 619-620. https://doi.org/10.1016/s0016-0032(34)90359-8
[26] US Department of Defense, M.-H.-5H. (1998). Metallic Materials and Elements for Aerospace Vehicle Structures, US Department of Defense, MIL-HDBK-5H, 1998.tle.

[27] Wang, H., Wu, P.D., Wang, J., Tomé, C.N. (2013). A crystal plasticity model for hexagonal close packed (HCP) crystals including twinning and de-twinning mechanisms. International Journal of Plasticity, 49: 36-52. https://doi.org/10.1016/j.ijplas.2013.02.016

[28] Wang, Y.Q., Yang, B., Han, J., Dong, F., Wang, Y.L. (2012). Localized corrosion of thermally aged cast duplex stainless steel for primary coolant pipes of nuclear power plant. Procedia Engineering, 36: 88-95. https://doi.org/10.1016/j.proeng.2012.03.015

[29] Žmak, I., Filetin, T. (2010). Predicting thermal conductivity of steels using artificial neural networks. Transactions of FAMENA, 34(3): 11-20. https://doi.org/10.1016/j.icheatmasstransfer.2016.03.00 8

[30] JMatPro_Logo Practical Software for Materials Properties. Sente Software Ltd. https://www.sentesoftware.co.uk/biblio.html, accessed on Jan. 17, 2020. 